\title{
$-0$ \\ School Choice and Competition: Evidence from The Netherlands
}

\author{
Elbert Dijkgraafl,2,3 \\ Stephanie van der Geest ${ }^{1,2}$ \\ Raymond H.J.M. Gradus ${ }^{4}$ \\ Matthijs de Jong ${ }^{1,2}$
}

I SEOR, Rotterdam;

2 Erasmus School of Economics, Erasmus University Rotterdam;

3 Tinbergen Institute;

4 VU University Amsterdam, ECRi, Erasmus University Rotterdam, and Research Institute for the CDA. 


\section{Tinbergen Institute}

The Tinbergen Institute is the institute for economic research of the Erasmus Universiteit Rotterdam, Universiteit van Amsterdam, and Vrije Universiteit Amsterdam.

Tinbergen Institute Amsterdam

Roetersstraat 31

1018 WB Amsterdam

The Netherlands

Tel.: +31(0)205513500

Fax: $+31(0) 205513555$

Tinbergen Institute Rotterdam

Burg. Oudlaan 50

3062 PA Rotterdam

The Netherlands

Tel.: + $31(0) 104088900$

Fax: $+31(0) 104089031$

Most TI discussion papers can be downloaded at http://www.tinbergen.nl. 


\title{
School choice and competition: Evidence from the Netherlands
}

\author{
10 November 2008
}

\section{Elbert Dijkgraaf ${ }^{*}$, Stephanie van der Geest ${ }^{*}$, Raymond H.J.M. Gradus ${ }^{* *}$ and Matthijs de Jong*}

\begin{abstract}
The literature suggests that competition among schools might increase quality. However, not much empirical evidence is present as only a few countries allow competition at a large scale. One exception is the Netherlands. Free parental choice is the leading principle of the Dutch education system since the beginning of the $20^{\text {th }}$ century. Based on panel data for the Netherlands we show that there is a relation between competition and student achievement in upper secondary education, but that it is negative. In addition, private schools have higher quality levels.
\end{abstract}

JEL: H70, I20

* SEOR and Erasmus School of Economics, Erasmus University Rotterdam, Room H 7-25, P.O. Box 1738, 3000 DR Rotterdam, The Netherlands, Tel: +31 104082590 Fax: +31 10 4089650, Email: dijkgraaf@few.eur.nl, Web: www.ecri.nl ${ }^{* *}$ VU University Amsterdam, ECRi (Erasmus University Rotterdam) and Research institute for the CDA 


\section{Introduction}

In the literature a discussion is going on whether competition among US schools will increase quality. Milton Friedman (1962) claimed already that school choice policies promise to align the incentives of school administrators with the demand of parents, and therefore may lead to a more efficient educational production. Absent a large voucher program in the United States, however, this prediction has been difficult to test. Therefore, in an influential paper Hoxby (2000) uses the concept of Tiebout choice, where parents choose between school districts, as the form of competition between US schools and examines the effect of varying sizes of school districts on students achievement. Her result suggests that competition enhances quality for elementary and secondary schooling. However, Rothstein (2007) shows that her results are sensitive for construction of the competition variables and claims that alternative constructions yield insignificant results. Moreover, Rothstein (2007, p. 2034) finds that Hoxby's specification is subject to selection bias because the sample excludes private schools students. In Hoxby (2007) these criticisms are disputed, but the discussion is still unsettled. Sandström and Bergström (2005) use data for public and private students and show that the increased parental choice in Sweden since 1992 supports the hypothesis that school results in public schools improve due to competition. However, if competition is measured by the commonly used Herfindahl-Hirschman concentration index with districts' enrollments as their market shares than the results are sometimes negative and sometimes insignificant. Also in Sweden the voucher program is small as only $7 \%$ of students were enrolled in a private school.

In the Netherlands the model of free parental choice between different types of schools has been present after the historic national school dispute ('schoolstrijd') came to an end in 1917 (see Kossmann, 1978). After that period parental choice and equal opportunities of public and private schools is even guaranteed in the Dutch constitution. In the Netherlands, private primary and secondary schools are run by independent non-profit boards, and abide by practically the same rules as public schools. Private schools are fully financed by the government at exactly the same level as public schools and for both based on the number of students. Many, but not all, private schools have a religious background. Parents are free to choose any public or private school, although the law permits religious schools to ask that parents agree with their background. Free choice is used very often as currently only $27 \%$ of students are at public schools. A country with a similar system is Belgium, where the system 
appeared in 1958 after also a prolonged battle between religious and secular political parties (see also Kossmann (1978, p. 273)).

Given the long history of competition between schools in the Netherlands, one would expect that effects on quality, if present, are visible. This is unsure, however, as the effect of competition on quality has never been systematically analyzed. In this paper we try to fill this gap based on data for secondary schools for the period 2002-2006. We use datasets of the Dutch Ministry of Education and the national monitoring agency for education ("Onderwijsinspectie"). We measure school quality by three achievement variables; the average score in the nationwide final exams, the percentage of students that obtain a diploma and the percentage of students finishing without delay. Surprisingly, for all three measures we find evidence for a negative relation with competition.

The article is organized as follows. In the second paragraph we discuss the methodology and the available data. In the third paragraph the estimation results are presented. In the fourth paragraph the robustness of the results is discussed. In the fifth paragraph some conclusions are drawn.

\section{Methodology and Data}

We estimate an equation with on the left-hand side an indicator for the average school performance and on the right-hand a constant term, the competition variable, school characteristics and socio-economic variables for the neighborhood where the school is located as a proxy for unobserved differences in student population (see, for example, Hoxby, 2000). ${ }^{1}$ As data are available for 2002-2006, we estimate a panel model using both the crosssection and the time-related variation. For each achievement indicator we estimate the following equation:

$\mathrm{Q}_{\mathrm{i}, \mathrm{t}}=\alpha+\beta \mathrm{CI}_{\mathrm{i}, \mathrm{t}}+\gamma \mathrm{S}_{\mathrm{i}, \mathrm{t}}+\lambda \mathrm{P}_{\mathrm{i}, \mathrm{t}}+\mathrm{c}_{\mathrm{i}}+\mathrm{d}_{\mathrm{t}}+\varepsilon_{\mathrm{i}}$

where $\mathrm{Q}_{\mathrm{i}, \mathrm{t}}$ measures student achievement, $\mathrm{CI}_{\mathrm{i}, \mathrm{t}}$ measures competition, $\mathrm{S}_{\mathrm{i}, \mathrm{t}}$ is a vector of school characteristics, $\mathrm{P}_{\mathrm{i}, \mathrm{t}}$ a vector of socio-economic variables of the neighborhood where the

\footnotetext{
${ }^{1}$ Hoxby $(2000,1213)$ uses school productivity (natural logarithm of per-pupil spending) as an explanatory variable. However, in the Netherlands all schools are equal funded by the government and therefore this term can be omitted.
} 
school is located, $c_{i}$ are time-invariant regional fixed effects (with one region as the benchmark), $d_{t}$ are time fixed effects (with 2002 as benchmark) and $\varepsilon_{\mathrm{i}}$ is an error term. In the Netherlands a distinction can be made between school boards (or competent authorities), schools and school locations. It is possible that a school board can comprise several schools and that a school has several locations. All variables are measured at the lowest level, for each school location $\mathrm{i}$ and year $\mathrm{t}$. We have data for all school locations. The total panel includes 2,418 observations for HAVO and 2,545 for VWO. We loose some observations due to data availability. ${ }^{2}$

At the average age of 12, students finish primary education and enroll, according to their own abilities, in one of three levels of secondary education: pre-vocational secondary education (VMBO), (senior) general secondary education (HAVO) or pre-university education (VWO). Admission of students is based on a nationwide test at the end of primary school and on advice of the primary school teachers. In this article, VMBO is not taken into account due to a large system change in $2000 .{ }^{3}$ HAVO with duration of five years is intended as preparation for higher professional education ( $\mathrm{HBO}$, similar to College) and VWO with duration of six years is intended to prepare for university. In most schools the choice between HAVO and VWO is made after the first two or three years of secondary education.

A bottleneck in some studies about the correlation between competition and quality is the availability of good data. However, based on administrative data of the national monitoring agency for education we are able to distinguish between three school performance measures as the dependent variable: the average central exam score based on a national exam in the final year that is the same for all Dutch schools, the percentage of students who graduated and the percentage of students who graduated without delay. In Table 1 the summary statistics are shown for HAVO and VWO.

We take as a measure for competition the so-called Herfindahl-Hirschman-Index (HHI). The HHI we use is based on the share $\left(\mathrm{s}_{\mathrm{i}}\right)$ of the school locations enrollment in total enrollment within a pre-defined geographic area: ${ }^{4}$

\footnotetext{
${ }^{2}$ For HAVO there are 1,947 observations (for 462 school locations) for central exam score and the percentage of students with diploma and 1,863 observations for the percentage of undelayed persons. For VWO there are 2,029 observations (for 498 school locations) for central exam score and the percentage of students with diploma and 1,916 observations for the percentage of undelayed persons.

${ }^{3}$ The VMBO school type was introduced in the 1999/2000 school year and comprises the former pre-vocational (VBO) and junior secondary school (MAVO) school types.

${ }^{4}$ For the market shares $\left(\mathrm{s}_{\mathrm{i}}\right)$ we take only into account students from their fourth year on.
} 


$$
H H I=\sum_{i=1}^{n} S_{i}^{2}
$$

School locations within a distance of 10 kilometers are taken into account. ${ }^{5}$ Other distances and measures are taken into account in the robustness analyses. The HHI varies between zero and one. A value of (nearly) zero indicates that there are many relatively equal-sized school locations in the relevant market. A value of one indicates that the school is monopolist. In the estimations we use a negative HHI (-HHI) as this is easier to interpret (an increase in competition corresponds with an increase of this measure).

Table 1: Descriptive statistics quality variables, years 2002-2006

\begin{tabular}{lrrrrr}
\hline & Observations & Average & Maximum & Minimum & St.dev. \\
\hline HAVO & & & & & \\
Central exam score & 1,947 & 6.2 & 7.2 & 4.7 & 0.25 \\
Percentage graduated & 1,947 & 90 & 100 & 7 & 7.28 \\
Percentage undelayed & 1,863 & 60 & 93 & 11 & 12.34 \\
& & & & & \\
VWO & & & & & \\
Central exam score & 2,029 & 6.4 & 8.2 & 5.0 & 0.29 \\
Percentage graduated & 2,029 & 93 & 100 & 20 & 6.77 \\
Percentage undelayed & 1,916 & 64 & 96 & 9 & 11.79 \\
\hline
\end{tabular}

In Table 2 descriptive statistics of the HHI indexes are given. On average the HHI has a value of 0.34 for HAVO and 0.33 for VWO. For both the HAVO and VWO $13 \%$ of the school locations has an index lower than 0.1 . An index between 0.1 and 0.2 applies to $26 \%$ of HAVO and $29 \%$ of VWO locations. For HAVO $35 \%$ of the school locations have an index between 0.2 and 0.5 and for VWO this is $34 \%$, and thus these markets are concentrated. ${ }^{6}$ For $26 \%$ of HAVO locations and for $23 \%$ of VWO locations markets are highly concentrated with a HHI of 0.5 or more. These schools are located in rural areas. According to this measurement, half of these schools is a monopolist. This means that competition differs a lot per region, which gives our analysis much power as we in fact use the differences between regions to estimate the effect of competition on quality.

\footnotetext{
${ }^{5}$ In US-literature the HHI is mostly based on a municipality or a district. In the Netherlands competition takes place within a certain geographic area as municipalities are much closer to each other. The distances between school locations are calculated using a standard route planner. The average distance Dutch students travel according to Statistics Netherlands is 10 kilometers.
} 
Table 2: Share of school locations with a high or low level of competition

\begin{tabular}{lrrr}
\hline & & \multicolumn{2}{c}{ Share of all school locations } \\
& HHI & HAVO & VWO \\
\hline High level of competition & $<0.1$ & 13 & 13 \\
& 0.1 tot 0.2 & 26 & 29 \\
Low level of competition & 0.2 tot 0.5 & 35 & 34 \\
& 0.5 tot 0.9 & 14 & 13 \\
Monopoly & 1.0 & 12 & 11 \\
Total & & 100 & 100 \\
\hline
\end{tabular}

The first school characteristic we correct for in the estimations is scale. ${ }^{7}$ In our model we include the SCALE of the BOARD (the number of schools per board), the SCHOOL which the location is part of (the total number of students) and the scale of the LOCATION (the number of students studying HAVO or VWO at the location). ${ }^{8}$ For VWO we also include a dummy if the school location is a so-called GYMNASIUM. A gymnasium focuses on the best students, who are usually taught in separate classes. ${ }^{9}$ See Table 3 for descriptive statistics.

A second characteristic we correct for in the estimations is school denomination. In the Netherlands we can distinguish between private (73\%) and public schools (27\%). Public schools have the obligation to be neutral, while private schools can have a self chosen denomination. Most private schools have a religious denomination such as ROMAN CATHOLIC (27\% of total) or PROTESTANT (17\%). Some private schools $(10 \%)$ do not have a religious denomination and are NEUTRAL. One sixth of all schools have another denomination such as Orthodox Protestant, Anthroposophy, Islamic ${ }^{10}$ or a combination of several denominations. On numerical grounds these smaller denominations are combined in the group OTHER. In the estimates we include a dummy per denomination taking public

\footnotetext{
${ }^{6}$ US regulators use a value of 0.18 to indicate concentrated markets.

${ }^{7}$ The effects of scale are not influenced by the correlation with competition. Estimations without competition variables or scale variable do not lead to other conclusions, while the correlation between scale and competition is low ( 0.14 for HAVO and 0.10 for VWO).

${ }^{8}$ We tested for multi-collinearity between these variables and did not find any indication for this.

${ }^{9}$ In the Netherlands, gymnasium students ( $8 \%$ of the VWO students) study the same subjects as their other VWO counterparts, with the addition of compulsory Ancient Greek, Latin and history of the Ancient Greek and Roman culture and life.

${ }^{10}$ Currently there are only a few Islamic schools. Excluding these observations, as some of them have a much lower quality, does not change the results.
} 
schools as a benchmark. We include also a dummy (IRREGULAR METHOD) if a school uses a special method of education such as the Dalton or Montessori method.

Table 3.a: Descriptive statistics other variables HAVO

\begin{tabular}{lrrrr}
\hline & Average & Maximum & Minimum & Std. Dev. \\
\hline Scale location & 316 & 1,203 & 2 & 143 \\
Scale school & 2,083 & 6,026 & 38 & 1,088 \\
Scale board & 12.94 & 74.00 & 1.00 & 20.29 \\
D2002 & 0.21 & 1.00 & 0.00 & 0.40 \\
D2003 & 0.20 & 1.00 & 0.00 & 0.40 \\
D2004 & 0.20 & 1.00 & 0.00 & 0.40 \\
D2005 & 0.20 & 1.00 & 0.00 & 0.40 \\
D2006 & 0.19 & 1.00 & 0.00 & 0.39 \\
Roman Catholic & 0.26 & 1.00 & 0.00 & 0.44 \\
Neutral & 0.12 & 1.00 & 0.00 & 0.32 \\
Protestant & 0.18 & 1.00 & 0.00 & 0.39 \\
Other & 0.18 & 1.00 & 0.00 & 0.39 \\
Irregular method & 0.07 & 1.00 & 0.00 & 0.25 \\
Girls & 0.51 & 0.83 & 0.25 & 0.05 \\
City 1 & 0.14 & 1.00 & 0.00 & 0.35 \\
City 2 & 0.22 & 1.00 & 0.00 & 0.41 \\
Bad neighborhood & 0.02 & 1.00 & 0.00 & 0.13 \\
Foreigners & 0.10 & 0.57 & 0.00 & 0.09 \\
Income & 13.56 & 28.70 & 9.35 & 2.69 \\
\hline
\end{tabular}

In general no socio-economic data on characteristics of the student population are available at the school level. Therefore we use data that is available for the zip code where the school is located. ${ }^{11} \mathrm{We}$ include the following socio-economic characteristics: a dummy to indicate if the school is in one of the four largest cities (CITY 1) ${ }^{12}$, or in one of the 21 largest cities (CITY 2) ${ }^{13}$, the number of non-western foreigners per 100 inhabitants (FOREIGNERS), a dummy if the school location is located in a bad neighborhood (BAD

\footnotetext{
${ }^{11}$ Zip codes in the Netherlands are alphanumeric, consisting of four digits (followed by two letters). These four digit zip codes are geographic areas of towns or municipalities and the Netherlands has more than 4,000 of such areas. The average size of this area is 10.3 squared kilometres.

${ }^{12}$ Amsterdam, Rotterdam, the Hague and Utrecht.

${ }^{13}$ This variable is included in difference with CITY1. The largest of these cities has 210,000 inhabitants, the smallest 118,000.
} 
NEIGHBORHOOD) $^{14}$ and the average income in 1000 euros (INCOME). The only demographic information available at the school level for the whole period is gender (GIRLS). ${ }^{15}$ The data for the socio-economic characteristics for each zip code are obtained from Statistics Netherlands. See Table 3 for descriptive statistics.

Table 3.b: Descriptive statistics other variables VWO

\begin{tabular}{lrrrr}
\hline & Average & Maximum & Minimum & Std. Dev. \\
\hline Scale location & 355 & 1,553 & 4 & 202 \\
Scale school & 1,988 & 6,026 & 38 & 1,119 \\
Scale board & 12.59 & 74.00 & 1.00 & 19.85 \\
Gymnasium & 0.08 & 1.00 & 0.00 & 0.27 \\
D2002 & 0.21 & 1.00 & 0.00 & 0.40 \\
D2003 & 0.20 & 1.00 & 0.00 & 0.40 \\
D2004 & 0.20 & 1.00 & 0.00 & 0.40 \\
D2005 & 0.20 & 1.00 & 0.00 & 0.40 \\
D2006 & 0.19 & 1.00 & 0.00 & 0.39 \\
Roman Catholic & 0.26 & 1.00 & 0.00 & 0.44 \\
Neutral & 0.11 & 1.00 & 0.00 & 0.31 \\
Protestant & 0.18 & 1.00 & 0.00 & 0.38 \\
Other & 0.17 & 1.00 & 0.00 & 0.37 \\
Irregular method & 0.06 & 1.00 & 0.00 & 0.24 \\
Girls & 0.54 & 1.00 & 0.32 & 0.05 \\
City 1 & 0.14 & 1.00 & 0.00 & 0.35 \\
City 2 & 0.22 & 1.00 & 0.00 & 0.42 \\
Bad neighborhood & 0.02 & 1.00 & 0.00 & 0.12 \\
Foreigners & 0.10 & 0.57 & 0.00 & 0.09 \\
Income & 13.70 & 28.70 & 9.35 & 2.80 \\
\hline
\end{tabular}

\section{Results}

Table 4 presents the estimations results based on OLS. For all three achievement indicators a negative relationship is found between quality and competition, which is highly significant for all cases. These results suggest that less competition improves the quality of education. However, the effects are not large. If competition increases from monopoly $(\mathrm{HHI}=1)$ to full competition $(\mathrm{HHI}=0)$ the average central exam score decreases with 0.09 in HAVO and 0.10

\footnotetext{
${ }^{14}$ These are the so-called Vogelaarwijken, named after the Minister for Housing, Communities and Integration who decided to give these neighborhoods extra money as they have major problems.
} 
in VWO. With the same change, the percentage of graduated students decreases with 3\%point for HAVO and 2\%-point for VWO and the percentage undelayed students decreases with 5\%-point for HAVO and 3\%-point for VWO. If we assume a smaller change, i.e. two schools now enter a market where already two schools were present (HHI decreases from 0.50 to 0.25 ) then the average central exam scores of both school types decrease with 0.02 . The percentage of graduated and undelayed students decreases in this case with 1\%-point. This means that, although we find a significant relationship between competition and quality, the effects are rather small.

Table 4.a: Estimation results HAVO

\begin{tabular}{|c|c|c|c|}
\hline & Central exam score & Share graduated & Share undelayed \\
\hline -HHI & $-0.09(0.03)^{* * *}$ & $-0.03(0.01)^{* * *}$ & $-0.05(0.01)^{* * *}$ \\
\hline Scale location & $0.04(0.04)$ & $0.01 \quad(0.01)$ & $0.03(0.02)^{* *}$ \\
\hline Scale school & $-0.01 \quad(0.01)$ & $0.00(0.00)$ & $0.00(0.00)$ \\
\hline Scale board & $0.00 \quad(0.00)$ & $0.00 \quad(0.00)$ & $0.00 \quad(0.00)$ \\
\hline Roman Catholic & $0.09(0.02)^{* * *}$ & $0.02(0.01)^{* * *}$ & $0.04(0.01)^{* * *}$ \\
\hline Neutral & $0.09(0.02)^{* * *}$ & $0.02(0.01)^{* * *}$ & $0.04(0.01)^{* * *}$ \\
\hline Protestant & $0.10(0.02)^{* * *}$ & $0.02(0.00)^{* * *}$ & $0.03(0.01)^{* * *}$ \\
\hline Other & $0.09(0.02)^{* * *}$ & $0.01(0.01)^{* *}$ & $0.05(0.01)^{* * *}$ \\
\hline Irregular method & $0.07(0.02)^{* * *}$ & $0.01 \quad(0.01)$ & $0.00(0.01)$ \\
\hline Girls & $-0.25(0.11)^{* *}$ & $-0.09(0.03)^{* * *}$ & $0.11(0.06)$ \\
\hline City 1 & $-0.04(0.02)$ & $-0.02(0.01)^{* * *}$ & $-0.05(0.01)^{* * *}$ \\
\hline City 2 & $0.01 \quad(0.02)$ & $0.00 \quad(0.00)$ & $0.00 \quad(0.01)$ \\
\hline Bad neighborhood & $-0.14(0.04)^{* * *}$ & $-0.05(0.01)^{* * *}$ & $-0.07(0.02)^{* * *}$ \\
\hline Foreigners & $-0.005(0.001)^{* * *}$ & $-0.001(0.000)^{* * *}$ & $-0.002(0.000)^{* * *}$ \\
\hline Income & $-0.003(0.002)$ & $-0.000(0.001)$ & $-0.002(0.001)^{* *}$ \\
\hline Dummy 2003 & $0.01 \quad(0.02)$ & $0.01 \quad(0.00)$ & $0.03(0.01)^{* * *}$ \\
\hline Dummy 2004 & $0.00(0.02)$ & $0.01(0.00)^{* * *}$ & $0.06(0.01)^{* * *}$ \\
\hline Dummy 2005 & $-0.07(0.02)^{* * *}$ & $0.00(0.00)$ & $0.09(0.01)^{* * *}$ \\
\hline Dummy 2006 & $-0.13(0.02)^{* * *}$ & $-0.01(0.00)^{* *}$ & $0.11(0.01)^{* * *}$ \\
\hline $\mathrm{C}$ & $6.39(0.08)^{* * *}$ & $0.94(0.02)^{* * *}$ & $0.55(0.04)^{* * *}$ \\
\hline $\mathrm{R}^{2}$ & 0.22 & 0.15 & 0.21 \\
\hline Observations & 1,947 & 1,947 & 1,863 \\
\hline
\end{tabular}

\footnotetext{
${ }^{15}$ Only for limited years we have school data on the number of non-western foreigners. Including this variable
} therefore reduces the number of observations considerably, but does not influence our conclusions. 
Table 4.b: Estimation results VWO

\begin{tabular}{|c|c|c|c|}
\hline & Central exam score & Share graduated & Share undelayed \\
\hline -HHI & $-0.10(0.03)^{* * *}$ & $-0.02(0.01)^{* *}$ & $-0.03(0.01)^{* *}$ \\
\hline Scale location & $0.24(0.03)^{* * *}$ & $0.02(0.01)^{* * *}$ & $0.08(0.02)^{* * *}$ \\
\hline Scale school & $-0.00(0.01)$ & $0.00(0.00)$ & $0.00(0.00)$ \\
\hline Scale board & $0.00(0.00)$ & $0.00(0.00)$ & $0.00(0.00)$ \\
\hline Gymnasium & $0.28(0.03)^{* * *}$ & $0.02(0.01)^{* * *}$ & $0.06(0.01)^{* * *}$ \\
\hline Roman Catholic & $0.01 \quad(0.02)$ & $0.01 \quad(0.00)$ & $0.03(0.01)^{* * *}$ \\
\hline Neutral & $0.06(0.02)^{* * *}$ & $0.01 \quad(0.01)$ & $0.03(0.01)^{* * *}$ \\
\hline Protestant & $0.06(0.02)^{* * *}$ & $0.01(0.00)^{* * *}$ & $0.03(0.01)^{* * *}$ \\
\hline Other & $0.06(0.02)^{* * *}$ & $0.02(0.00)^{* * *}$ & $0.03(0.01)^{* * *}$ \\
\hline Irregular method & $0.00(0.02)$ & $0.00 \quad(0.01)$ & $0.01 \quad(0.01)$ \\
\hline Girls & $0.07 \quad(0.12)$ & $-0.03(0.03)$ & $0.12(0.06)^{* *}$ \\
\hline City 1 & $0.00 \quad(0.02)$ & $-0.01(0.01)^{* *}$ & $-0.04(0.01)^{* * *}$ \\
\hline City 2 & $-0.01 \quad(0.02)$ & $-0.00(0.00)$ & $0.00 \quad(0.01)$ \\
\hline Bad neighborhood & $-0.30(0.05)^{* * *}$ & $-0.10(0.01)^{* * *}$ & $-0.06(0.02)^{* *}$ \\
\hline Foreigners & $-0.006(0.001)^{* * *}$ & $-0.001(0.000)^{* * *}$ & $-0.002(0.000)^{* * *}$ \\
\hline Income & $-0.004(0.003)$ & $-0.000(0.001)$ & $-0.002(0.001)^{* *}$ \\
\hline Dummy 2003 & $-0.04(0.02)^{* *}$ & $0.00(0.00)$ & $0.03(0.01)^{* * *}$ \\
\hline Dummy 2004 & $0.06(0.02)^{* * *}$ & $0.01 \quad(0.00)$ & $0.05(0.01)^{* * *}$ \\
\hline Dummy 2005 & $-0.04(0.02)^{* *}$ & $0.01 \quad(0.00)$ & $0.08(0.01)^{* * *}$ \\
\hline Dummy 2006 & $-0.07(0.02)^{* * *}$ & $-0.01 \quad(0.00)$ & $0.09(0.01)^{* * *}$ \\
\hline $\mathrm{C}$ & $6.35(0.08)^{* * *}$ & $0.95(0.02)^{* * *}$ & $0.58(0.04)^{* * *}$ \\
\hline $\mathrm{R}^{2}$ & 0.20 & 0.16 & 0.21 \\
\hline Observations & 2,029 & 2,029 & 1,916 \\
\hline
\end{tabular}

Notes: Standard errors in brackets, ${ }^{* * *} f^{* * *}$ means significance at $10 \% / 5 \% / 1 \%$, models are estimated with regional fixed effects which are available upon request.

Scale effects are only found in a few cases. For the scale of the board and school we find insignificant results. For HAVO the coefficients of the scale of the school location are in most cases insignificant. For VWO the scale of the school location has a positive effect. VWO school locations that focus on gymnasium students have higher scores.

Interestingly, for private schools we find many positive effects compared with the benchmark public schools and these effects are often larger than the effect of competition. ${ }^{16}$ For HAVO this is the case for all denominations. For VWO positive and significant effects are found for protestant and other denominational schools for all quality variables. For Roman Catholic schools there is a positive effect on the percentage undelayed. Neutral

16 This need not be the result of better education, if private schools attract students with more initial endowments, learning capacities or a better motivation. We have no data to test this. 
private schools have a higher central exam score and a higher share of undelayed students. The positive effects on achievement for private Dutch schools, especially those with a religious denomination, have been well documented in the literature, although there are some differences. In an overview study, Dijkstra (1997) shows that the results of Roman Catholic schools are found at the top of the list. However, he does not correct for selection effects. For non-regular methods of education such as Dalton or Montessori there is only a positive effect for the central exam score for HAVO. For effects in time we see that especially the exam score declines over time but that the percentage of undelayed increases over time. ${ }^{17}$ Thus, there are fewer students with delay, but the price is a lower exam score.

Turning to the socio-economic characteristics, we find significant negative results if a school is located in a bad neighborhood or in a neighborhood with a high percentage of nonwestern foreigners. The dummies for large cities are mostly insignificant or rather small. Big city problems are probably concentrated in particular areas and are already captured by the other variables (foreigners and income). Only for HAVO (central exam score and percentage graduated) there is an indication that the gender effect is important, and that schools with more girls have lower results.

\section{The robustness analysis}

To analyze the robustness of the estimations we test for endogeneity and specification of the quality, competition and socio-economic variables. ${ }^{18}$ None of these issues drives our results.

One could argue that there is also an effect of quality on competition (that is, low quality performance of incumbent schools provokes entry of new school which increases competition). If this is the case, our OLS-estimations are biased. An alternative for OLS is IV-estimation where HHI is replaced by an instrument (as applied for instance by Sandström and Bergström (2005) and Hoxby $(2000,2007))$. However, for the Netherlands there are no adequate instruments and as stressed by Rothstein (2007) there is evidence that IV estimates are less precise than OLS and highly influenced by the chosen instrument. Furthermore, estimations we did with a system (based on maximum likelihood) allowing for the effect of quality on competition and estimations with delayed competition variables resulted in

\footnotetext{
${ }^{17}$ Only for VWO-2004 there is a significant positive effect on the exam scores.

${ }^{18}$ Full sensitivity analyses are available on request.
} 
comparable conclusions. The reported negative effect of competition on quality is therefore robust for endogeneity.

Second, it could be expected that our quality variables are biased as they are averaged over all subjects. It is possible that students make other subject choices in highly competitive areas. However, detailed analysis using the scores per subject reveals that a negative effect is found for nearly all subjects. For some subjects we find an insignificant effect, but a positive effect is never found.

Next, we test alternative assumptions for the competition variable. First, we decreased the radius of the relevant market (see equation 2). Second, competition is measured by the number of school locations in the market. Third, competition is measured at the level of the school instead of the school location. In all cases we find again a negative effect of competition on quality. Furthermore, we investigate whether cut-throat competition is important, but found no evidence for this. ${ }^{19}$ Another important issue is whether competition takes place between or within religious denominations. The literature shows that competition takes place between rather than within denominations in primary education (Driessen en van der Slik, 2001, 570) as the overall quality superiority of private schools is for most parents more important than the precise religious denomination. If we include in an extra HHI index only locations with the same denomination no significant results are found. The general HHI coefficient remains significant and negative in general. It seems that denominational schools in the Netherlands are attractive to both non-affiliated and affiliated parents. We also divide the sample into three subsamples depending on denomination (public, Roman Catholic, Protestant combined with other private schools). Again we find a negative relationship between competition and quality. Interestingly, this relation is stronger for Roman Catholic school locations than for Protestant and other private schools. For public schools this relation is especially significant for HAVO.

It could be argued that our results are driven by differences between rural and urban regions if these are not adequately included in the exogenous variables. However, if we distinguish between the most urbanized provinces of the Netherlands (Zuid-Holland, NoordHolland and Utrecht) and the rest of the Netherlands, we find in both samples the negative

\footnotetext{
${ }^{19}$ Cut-throat competition is tested by allowing for an U-shape relation between competition and quality (see also Aghion et al. (2005)).
} 
effect of competition on quality. If we exclude the $21^{\text {st }}$ largest cities from our sample the competition effects are even larger.

Finally, other combinations of exogenous socio-economic variables do not alter the results. ${ }^{20}$ Summarizing, the found negative relationship between competition and quality for the Dutch secondary schools is rather robust.

\section{Conclusions}

In the literature an interesting debate on the effect of competition between schools takes place. From a theoretical point of view it is argued that competition enhances quality as higher quality schools can gain market share. The empirical part of this discussion is based on countries where only a low level of competition is present. In the Netherlands free parental choice between all schools has been the leading principle since the school dispute in the beginning of the previous century allowing competition among schools. Nevertheless, a systematic analysis of the effect of this free parental choice on school achievement did not take place and this paper fills this gap for secondary education. Our conclusion is that there is a robust negative relation between competition and achievements of Dutch students. In addition, it is shown that private schools have a higher quality level.

At first sight the found negative relationship looks strange. Apparently, school achievement seems not to be the most important choice variable. There are different explanations for this finding. First, there is evidence that other choice variables are more important. Dutch schools seem to compete more with secondary elements such as sport, music facilities or the attractiveness of the building as enquiries show that these elements are at least as important for the choice parents make. If schools invest in these characteristics, they have less time and money for the primary process. This might result in the found relationship as schools in competitive areas have more incentives to invest higher amounts of time and money in secondary elements. Second, although there frequently is public discussion about quality, quality as measured by the official institutions might not be transparent for parents. However, since 2004, newspapers publish quality of good and bad schools explicitly and the quality variables are available on the internet. Still, these figures

\footnotetext{
${ }^{20}$ The following alternatives are tested: instead of a postal district we choose a fixed radius of 10 kilometres to calculate the socio-economic characteristics, we included population density, the number of employed per 100 inhabitants and the number of social security benefits below 65 per 100 inhabitants.
} 
might be used to sort out the bad and very good schools, leaving undecided the choice between average schools.

In future research there are several avenues to explore. First, future research should use broader measures of quality. It could be that competition has a positive effect on quality aspects that parents value. Second, it is interesting to investigate this relation for primary schools as well. Although one can argue that distance as a choice variable becomes more important given the age of the students, it is worthwhile to investigate the relation between competition and quality. Third, if data are available for more years, it is possible to investigate whether the found relationship still holds in a larger time span. The effect of public discussion and better transparency by internet might have positive effects after some years. 


\section{References}

\section{Aghion, Philippe, Nick Bloom, Richard Blundell, Rachel Griffith and Peter Howitt.}

2005. "Competition and innovation: an inverted-U relationship," Quarterly Journal of Economics, 120(2): 701-28.

Dijkstra, Anne Bert. 1997. “Onderwijskansen en richting van de school.” In Verzuiling in het onderwijs. Actuele verklaringen en analyse, ed. Anne Bert Dijkstra, Jaap Dronkers, and Roelande Hofman, 144-84, Groningen: Wolters Noordhoff.

Driessen, Geert and van der Slik, Frans. 2001. "Religion, denomination, and education in the Netherlands: Cognitive and noncognitive outcomes after an era of secularisation." Journal for the Scientific Study of Religion, 40(4): 561-72.

Friedman, Milton. 1962. Capitalism and Freedom. Chicago: University of Chicago Press.

Hoxby, Caroline M. 2000. "Does competition among public schools benefit students and taxpayers?" American Economic Review, 90(5): 1209-1238.

Hoxby, Caroline M. 2007. "Does competition among public schools benefit students and taxpayers? A reply." American Economic Review, 97(5): 2038-2055.

Kossmann, Ernst H. 1978. The Low Countries 1780-1940. Oxford: Oxford University Press.

Rothstein, Jesse. 2007. "Does competition among public schools benefit students and taxpayers? Comment.” American Economic Review, 97(5): 2026-2037.

Sandström, F. Mikael and Frederik Bergström. 2005. "School vouchers in practice: Competition will not hurt you." Journal of Public economics, 89(2/3): 351-380. 